Our Nature (2009) 7:26-31

\title{
Nest and Nidification Activities of the Spoonbill Platalea leucorodia in Westerghat Region of Shimoga, Karnataka
}

\author{
G.Y. Dayananda and B.B. Hosetti \\ Department of Applied Zoology, Biosciences complex, Jnana Sahyadri, Shankaraghatta-577 451, \\ Shimoga, Karnataka, India
}

Received: 18.02.2009, Accepted 13.04.2009

\begin{abstract}
Nest and nidification behaviour of the Spoonbill, Platlea leucorodia (FamilyThreskiornithidae) was studied for three seasons during 2003-2005, at Gudavi Bird Sanctuary (GBS), Gudavi village, Sorab, Karnataka. The GBS harbored about 12 thousand birds of various species, of these, only 10-12 pairs of Spoonbills were breeds every year in this place. There were five Spoonbill nests, of which one was old egret nest and the four were newly built by Spoonbills. The clutch size was two to three in each nest $(\mathrm{N}=5)$ and the shape of the egg was oval, white with small brown spots. The nesting activity usually starts in the month of late July and ends during December. The nesting activity, nest site selection, nesting habitat, nesting material, nest size, and nidification of Platalea leucorodia are discussed in this paper.
\end{abstract}

Key words: Spoonbill, Platalea leucorodia, Nest and Nidification, Gudavi Bird Sanctuary, Shimoga.

\section{Introduction}

The Spoonbill (Platalea leucorodia) is spread throughout India. It is a colonial breeder, nesting on moderate to tall sized trees and shrubs, such as Vitex leucoxylon and Kirganelia reticulata which stand amidst or near water bodies (Ali and Ripley, 1983; Hancock, 1992). According to Ali and Ripley (1983), the breeding season of the Spoonbill in South India begins during second week of July and extends upto November, depending on the monsoon conditions. These birds are characterized by having a long neck, long leg, snow white marshy plumage, black and yellow spoon shaped bill and pale yellowish brown patch on fore neck with full nuchal crest in the breeding season. These are gregarious birds; they share nesting places with Ibises, Cormorants, Herons and Egrets. The nesting site selection is an important factor in breeding success of bird species (Price and Jamdar, 1991; Li and Martin, 1991; Ramachandran and Vijayan, 1994). The nesting activity is an important component of breeding behaviour in birds. Though it is difficult to determine that which exact factors govern the selection of sites on particular trees for nesting, there exists some evidence that preference was shown by certain water birds. There were about 25 Spoonbills breed every year in Gudavi Bird Sanctuary.

Lack of detailed information on the species poses problems for its conservation. Comprehensive research to explain the apparent difference between the known numbers of wintering and breeding individuals has not been possible yet, and the Spoonbills breeding biology itself has not been known (Chang Jong Ryol et al, 
2000). In this paper we tried to fill the lacunae on breeding behavior of Spoonbills in the GBS from courtship to nidification activities.

\section{Study area}

The Gudavi Bird Sanctuary is one of the well know bird sanctuaries of Karnataka which was notified on AHFF-262-fwl 86/ on 10:07:1989. It is located at $13 \mathrm{~km}$ away from Sorab City and $0.5 \mathrm{~km}$ away from Gudavi village. This sanctuary occupies a water spread area of $33 \mathrm{ha}$, in rainy season, out of the total 73.68 ha (Figure 1). Remaining area is moist deciduous forest inhabiting various tree species. The sanctuary located between latitude $14^{\circ} 25^{\prime} 59^{\prime \prime}$ to $14^{\circ} 26^{\prime} 41^{\prime \prime} \mathrm{N}$ and longitude $75^{\circ} 6^{\prime} 43^{\prime \prime}$ to $75^{\circ} 25^{\prime} 28^{\prime \prime} \mathrm{E}$.

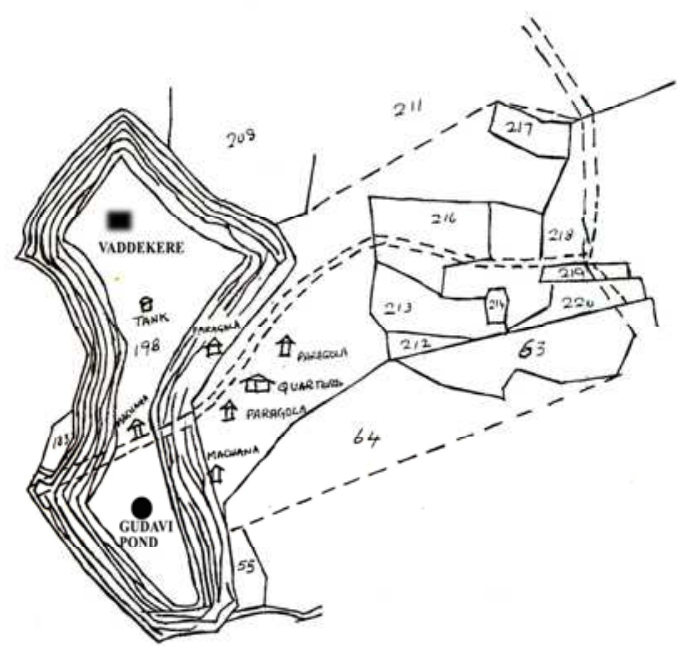

Figure 1. Gudavi Bird Sanctuary

\section{Vegetation}

The entire area was covered with dense moist deciduous forest and due to intensive protection efforts by the Forest Department, the area has some greenery. Apart from this Gudavi sanctuary embodies diversified vegetation that attracted the migratory birds to take shelter and space to construct their nests for breeding. The vegetation of GBS comprised of marshy plants and hydrophytes. The trees and shrubs partially submerged and provide suitable nesting grounds for wetland birds. These nesting sites also provide the highest security from the predators.

\section{Materials and methods}

The present study was carried out for three breeding seasons 2003, 2004 and 2005 from July to December. Observations were made both morning and evening, before sunrise to sunset (Spoonbill stays). The study was conducted with $5 \times 50$ binocular and available field guides. The breeding behaviour of active pairs of spoonbills was studied by monitoring the nest site from early morning to late evening for consecutive days. Nidification activities, such as the number of hours of labour for nest construction, the type and amount nesting material collected during the busy hours of nidification, average time spent in gathering sticks for nest building, average time to carry the nesting material from its source to the nest, nest inspection and rearrangement activities by nest occupants were recorded to determine the role of both sexes in nesting activities.

\section{Results and discussion}

\section{Nesting season}

Observations were made during breeding season, i.e., from July to November, on the nesting of Spoonbill. However, in these years 2003, 2004 and 2005, observations of the early nesting and late nesting were not made because the area has received rain water during the same period of Spoonbill breeding. These birds start the nesting 
activity in July, in Gudavi Bird Sanctuary. According to Lark (1968) the breeding season is characteristic of the geographical area rather than a particular species specific, accordingly, the breeding season of the Spoonbill varied over different geographical areas, usually, nesting took place after the rains and varied according to the monsoon. Ali (1996) described the nesting season of Spoonbill as variable between July and November in South India. The present observations were recorded to determine the breeding season of Spoonbill from late July to second week of December. Improvement of breeding conditions through good rains enhanced the reproductive vigor (Chavda, 1997). The copulation process was more intensive during nidification.

The male initiated courtship by preening the female's cheek, head and neck. His mate responded by rubbing the males' head and neck. This continued for 4-5 minutes, after which the male raised his head plumage, grasped the female bill about the mid point and initiated copulation for 8-10 seconds. This process continued until the day before the final egg was laid. The extra pair copulation was not observed. The nest repair continued till breeding was over or till fledging took place.

\section{Nesting site selection}

The nesting activities assumed in the Gudavi area during the $3^{\text {rd }}$ week of July. The nesting site selection was a part of the courtship behaviour. On arrival to the area each pair searched and inspected the vegetation and nesting in the territory. These began to fly over the entire nesting area, silently and selected a suitable place for nesting. This took almost in 4 to 5 days for both the partners. Once a nesting site on a tree was selected, immediately they took up the construction activities. During three breeding seasons the birds found changing their nesting sites. The selected nest sites were characterized by significantly high richness of the canopy and provided an ideal nesting platform. Those birds returned every year to breed regularly to these places became traditional nesting sites. It may be due to the availability of plenty of food sources in the surrounding area and safety for nest and nestlings (Parasharya and Naik, 1990; Carrascal et.al., 1993; Gadhavi and Soni, 2002; Yahya, 2001). In Gudavi sanctuary, there were 15-16 nesting pairs, almost all of them breed on this sanctuary every year.

\section{Nesting Habit}

In Gudavi Bird Sanctuary 12 species of plants were used for nesting. Out of these, three species were trees and four species shrubs, all were found within in the waterspread area. The Spoonbill utilized mainly two species for nesting and remaining species were present in and around the sanctuary. The Spoonbills preferred Kirganelia reticulata and Vitex leucoxylon for nesting, because it was easy to construct the nest on them and provided dense canopy and an ideal nesting platform for these birds (Figure 2).

The Spoonbills always built nests at the top level of trees that are standing in or around the water bodies. However, nests were also observed on top of partially submerged shrubs (Ali and Ripley, 1983). Some times the thick canopy also prevented the chicks from falling directly to the water or ground. In the case of GBS, the canopy cover of Kirgenelia reticulata provided a firm protection by minimizing the direct heat from the open son. The well covered nest does not require the wing shading by 


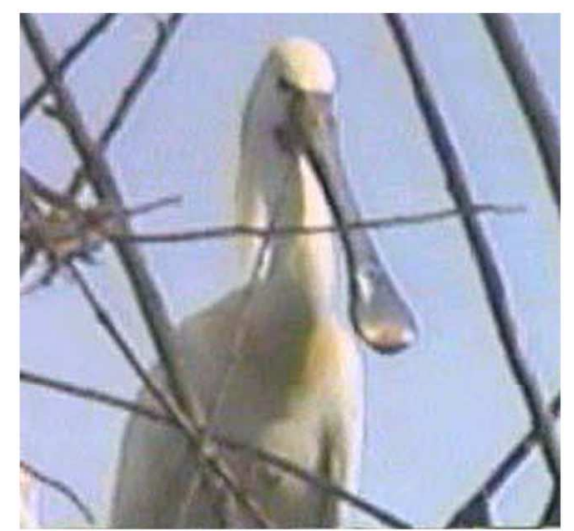

Spoonbill

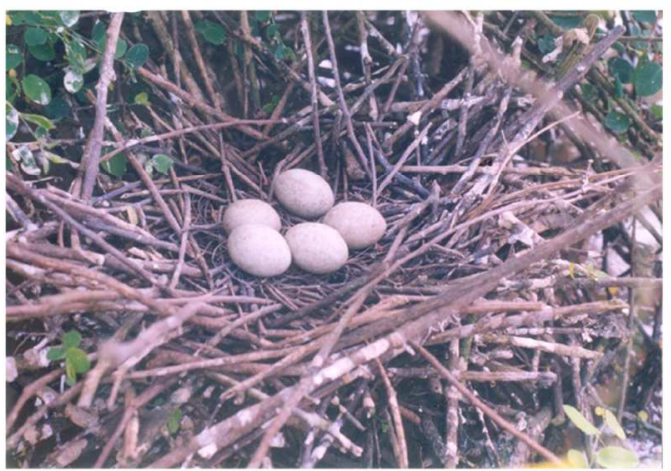

Eggs of Spoonbill

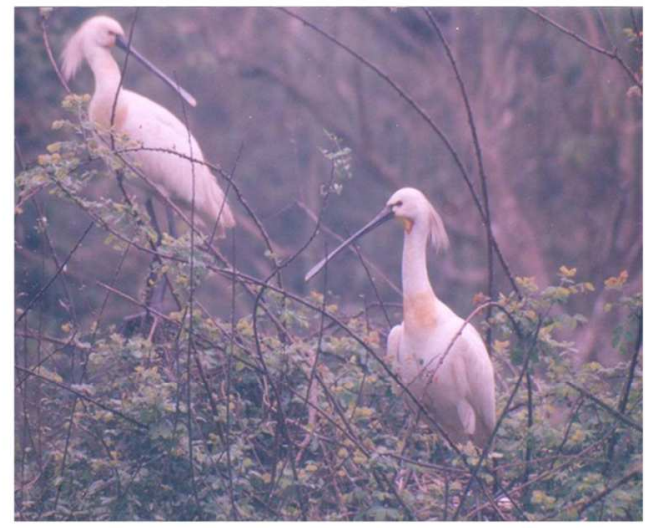

Breeding colony of Spoonbill

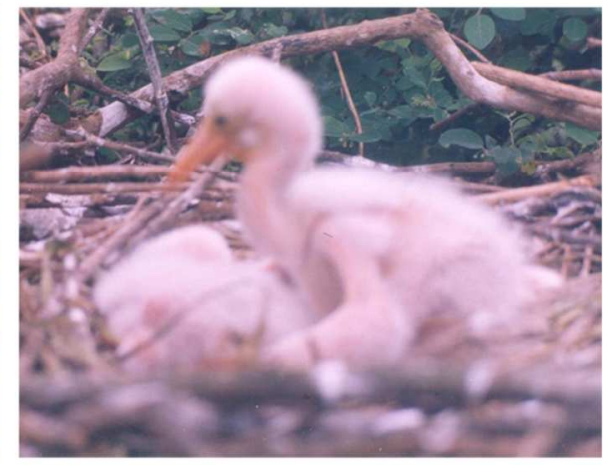

Chicks of Spoonbill

Figure 2. Nesting activities of Spoonbill.

the parents to their chicks which benefits the parents in conserving the energy.

\section{Nesting materials}

The nesting material varied from nest to nest and was dependent on the nesting site. They seldom brought materials to the nest, instead pulled out whatever materials available around the nest location. The spoonbill collected the nesting sticks from Acacia nilotica, Kirganelia reticulata, Bombax aroundinaceae, Phylanthus polyphyllus, Lantana india, Vitex leucoxylon and Eupotorium odoratum. The nesting material was available nearby the sanctuary. The other materials like feathers, grasses and leaves were also noticed in nests. The bulk of the nest material was the twigs of trees and shrubs. The parents collected different sized twigs from different trees. They were about $7.68 \% \quad(X=565.4$, $\mathrm{SD}=43.43, \mathrm{n}=5$ ) sticks used for a nest construction. Out of these $16.85 \%$ are large $(\mathrm{X}=32.4, \mathrm{SD}=5.46, \mathrm{n}=5) 14.57 \%$ medium 
G.Y. Dayananda and B.B. Hosetti / Our Nature (2009) 7: 26-31

$(\mathrm{X}=233.2, \quad \mathrm{SD}=33.99, \mathrm{n}=5)$ and $11.18 \%$ small $\quad(X=307.4, \quad S D=34.39, \quad n=5)$ respectively. In nest construction, the large twigs were used in basal part for a firm platform support or as a basement and just above the basement medium sized twigs were placed. The small and thin twigs were placed in and around the nest cup. The other materials like feather, grasses and leaves were used inside the nest cup as a soft bed for eggs and chicks and some times used for patchwork.

\section{Nest size}

The nest size varied from species to species and was dependent on the size of the birds. In spoonbill, the weight of the nest was ranged from $1750 \mathrm{gms}$ to $3050 \mathrm{gms}$ $(X=2480, S D=480.20, n=5)$, the length of the nest was 59 to $90 \mathrm{~cm}(X=74, S D=10.52)$ and diameter of the nest rim was 48 to 56 $\mathrm{cm}(\mathrm{X}=51.2, \mathrm{SD}=2.71)$. The diameter of the nest cup was 23 to $31 \mathrm{~cm} \quad(X=27.4$, $\mathrm{SD}=3.00)$ and depth of the nest cup was 2.5 to $4 \mathrm{~cm}(\mathrm{X}=3.06, \mathrm{SD}=0.55)$. Based on the study it revealed that, this place is more suitable for Spoonbills and very rich in canopy and sufficient amount raw materials for nesting (Figure 2).

\section{Nidification}

In some of the birds the breeding pair was assisted by helper for construct the nest. But, in the present case any helpers did not assist Spoonbill. Nests were built on wellbranched trees and shrubs of Vitex leucoxylon and Kirganelia reticulata. The Spoonbills were observed to construct the nest by placing 15-20 twigs as the basement substrate before egg laying and then continue to add more twigs during incubation too. The Spoonbill in GBS started the nest building process just after the sunrise and continued to before leaving for foraging, at around 10:30 to11:00 am. It was observed keenly that the male brought twigs to the nest and passed them to the female who arranged them in the order in the nest with the help of her bill. Addition of twigs was carried out in such a way that it may insure the chicks that do not fall out as the nests deteriorate during the progress of nesting period. These birds collected about 22-24 twigs every day, from the nesting trees and shrubs.

\section{Summary}

The Gudavi Bird Sanctuary provided nesting sites for about 35 of Spoonbills every year. The nesting site selection was the part of courtship behaviour and nesting activity was an important component of breeding behaviour. These birds return to their breeding home regularly and become traditional nesting sites for them. The availability of suitable feeding resources in the surrounding area and safe nesting sites attracted these birds to the same site. The nesting materials varied from nest to nest and influenced by the nesting site or canopy. Nest size also varied from species to species and dependent on size of the birds. The nest and nesting site selection is a most important factor for breeding success.

\section{References}

Ali, S. 1996. The book of Indian birds. Oxford University Press, Mumbai.

Ali, S.and Ripley 1983. Hand book of birds of India and Pakistan. Oxford University Press, Delhi. pp. 110-112.

Carrascal, L.M., L.M. Bautista and E. Lazaro 1993. Geographical variation in the density of the White Stork Ciconia ciconia in Spain: Influence of habitat stucture and climate. Biol. Conserv. 65: 83-87.

Chavda, P.B. 1997. Studies on some ecological aspects of the Indian Black ibis (Pseudibis papillosa Temminck) at Junagadh and its 
G.Y. Dayananda and B.B. Hosetti / Our Nature (2009) 7: 26-31

surrounding area. Saurashtra University, Rojkot, India. (Ph.D. Thesis)

Chong Jong-Ryol., Pak U-II., Tim chyu-Yon and Kim Tok-San 2000. The breeding biology of the Black faced Spoonbill Platalea minor. Wild bird society of Japan, Tokyo, Japan ( $2^{\text {nd }}$ ed.). pp. 11-18.

Hancock, J.A., J.A. Kushlan and M.P. Kahl 1992. Stork, Ibises and Spoonbills of the World. Academic Press, London. pp. 217-220.

Lark, D. 1968. Ecological adaptations for breeding in birds. Muthuen and Co., London.

Li, P. and T.E. Martin 1991. Nest site selection and nesting success of cavity nesting birds in high elevation forest drainage. Auk. 108: 405-418.

Parasharya, B.M. and R.M. Naik 1990. Ciconiforus birds breeding in Bhavnagar city, Gujarat; A Study of their nesting and plea for conservation. In Conservation in developing countries: Problems and prospects (Eds. J.C. Daniel and J.S. Serrao) Oxford University Press, Bombay. pp. 429-445.

Price, T. and N. Jamdar 1991. Breed ing biology of the yellow browned leaf warbler Phylloscopus inornatus on Kashmir. J. Bomb. Nat. Hist. Soc. 88(1): $1-16$

Ramachandran, N.K. and V.S. Vijayan 1994. Distribution and general ecology of the Sarus crane (Grus antigone) in Keoladeo National Park, Rajasthan. J. Bomb. Nat. Hist. Soc. 91: 211-222.

Yahya, H.A.S. 2001.Biology of Indian Barbets. Authors Press, New Delhi. pp. 97-99. 